\title{
BRAF V600E Mutations in Papillary Thyroid Carcinoma: Their Relation to Clinical Features and Oncologic Outcomes in A Single Cancer Centre Experience
}

Mahmoud Al-Masri ( $\square$ malmasri@khcc.jo)

Department of Surgery, King Hussein Cancer Center, Queen Rania St 202, Amman

Tawfiq Al-Shobaki

Department of Surgery, King Hussein Cancer Center, Queen Rania St 202, Amman

Hani Al-Najjar

Department of Surgery, King Hussein Cancer Center, Queen Rania St 202, Amman

Rafal Iskanderian

Department of Surgery, King Hussein Cancer Center, Queen Rania St 202, Amman

Enas Younis

Department of Internal Medicine, Endocrine, King Hussein Cancer Center, Queen Rania St 202, Amman

Niveen Abdallah

Department of Pathology \& Laboratory Medicine, King Hussein Cancer Center, Queen Rania St 202, Amman

Abdelghani Tbakhi

Department of Cell Therapy \& Applied Genomics, King Hussein Cancer Center, Queen Rania St 202, Amman

Hussam Haddad

Department of Pathology \& Laboratory Medicine, King Hussein Cancer Center, Queen Rania St 202, Amman

Awad Jarrar

Department of Surgery, King Hussein Cancer Center, Queen Rania St 202, Amman

Mohammad Al-Masri

School of Medicine, University of Jordan, Queen Rania St, Amman

\section{Research Article}

Keywords: BRAF, V600E, PTC, tumor

Posted Date: December 14th, 2020 
DOl: https://doi.org/10.21203/rs.3.rs-119519/v1

License: (c) (1) This work is licensed under a Creative Commons Attribution 4.0 International License. Read Full License 


\section{Abstract}

Introduction BRAF V600E is one of the most common mutations in Papillary Thyroid Cancer (PTC). Its clinical correlation has been extensively studied with contradictory results. The aim of this study is to evaluate the oncological impact of BRAF V600E mutation on a cohort of Middle Eastern PTC patients treated at a single institute.

Methods Patients with histologically confirmed PTC that were treated surgically between 2006 to 2015 were included in the study. Formalin fixed paraffin embedded tumor blocks were sectioned and tested for BRAF V600E mutation. Short- and long-term oncological outcomes were collected.

Results 128 patients ( $68 \%$ females) were included with a mean age of 38 years ( \pm 13.8$)$. Median follow-up was 50 months. BRAF V600E mutation was found in $71 \%$ of patientsI

The BRAF negative tumors were significantly larger than the BRAF positive $(3.47 \mathrm{~cm}$ versus $2.31 \mathrm{~cm}$ respectively, $P=0.009$ ). All other clinicopathological characteristics were comparable between BRAF V600E mutation positive and negative groups. The two groups showed similar 5-year Disease-free $(\mathrm{P}=$ $0.37)$ and Overall survival rates $(P=0.94)$.

Conclusion BRAF V600E mutation did not affect loco-reginal recurrence, distant metastasis, overall and disease-free survival. These results support the diversity of BRAF V600E significance among various ethnicities.

\section{Introduction}

Thyroid cancer, with its most prevalent papillary subtype, is the most common malignant endocrine tumor worldwide ${ }^{1}$. In Jordan, thyroid cancer ranked ninth among all cancers with an incidence of $2.9 \%$ in 2001 . This incidence raised to $4.3 \%$ in 2013 making thyroid cancer the 4th most common malignancy in Jordan 2. This change is also reflected by a similar increase worldwide. Papillary thyroid cancer (PTC) subtype had the lion's share of this increase and accounted for approximately 85 to $88 \%$ of all thyroid cancer diagnoses. The incidence of other subtypes remained unchanged ${ }^{3}$.

The reason behind this increase in incidence is controversial. A few have attributed this trend towards an abundant clinical surveillance, improved diagnostics such as high resolution thyroid ultrasound, bedside availability of such imaging modalities, an expansion in their indications, along with an increasing use of fine needle aspiration biopsy ${ }^{4}$.

An increased detection of occult papillary thyroid cancer on pathologic examination of thyroid glands removed for benign conditions and reported as thyroid cancer cases to national cancer registries may also contribute towards the increasing incidence of thyroid cancer ${ }^{5}$. 
Despite the increasing incidence, the mortality rates for well differentiated thyroid cancer remained relatively stable. The 30-year disease-specific survival rates can exceed ninety five percent. In-spite-of that, a subset of patients with metastatic disease have a glimmer outcome with a 5-year survival as low as $56 \%{ }^{6}$. Although treatment is often curative, there is a $15 \%$ recurrence rate over the course of 10 years, and approximately $10 \%$ of patients die as a result of disease progression 7,8 .

BRAF mutations, are the most common genetic events in thyroid cancer with the highest incidence in PTC. Various studies reported an incidence ranging between 29 to $88 \%$ of all PTC cases ${ }^{9}$. BRAF V600E is the most common of BRAF mutations. Its clinical correlation with PTC has been extensively studied with contradictory results ${ }^{10-13}$. The aim of this study is to evaluate the incidence and clinical impact of BRAF V600E mutation on a cohort of PTC treated at a single institute with disease free \& overall survival as the primary end point.

\section{Methods}

This is a retrospective chart review study approved by the Institutional Review Board (IRB) at King Hussein Cancer Center (KHCC). IRB (Ref: 15KHCC101). The KHCC IRB is guided by the principles described in the World Medical Association's Declaration of Helsinki (1964) and its amendments.

Because of the retrospective nature of the study and the lack of personal or clinical details of participants that compromise anonymity, consent was waived and the study was approved by King Hussein Cancer Center Institutional Review Board (IRB). The datasets used and/or analysed during the current study are available from the corresponding author on reasonable request.

\section{Study Cohort And Tumor Samples}

Patients with primary thyroid carcinomas were analyzed between the years of 2006 to 2015.

In all cases, curative hemithyroidectomy or total thyroidectomy with or without neck dissection was performed. Radio-active lodine was given according to institution guidelines.

All patients were regularly followed with physical examinations, thyroid function tests and neck ultrasonography every 6 to12 month after the initial surgery. If suspicious thyroid nodules or lymph nodes were found, ultrasound-guided fine needle aspiration cytology (US-FNAC) was used for evaluation.

Tumor-node-metastasis (TNM) staging was defined based on the eighth edition of the American Joint Committee on Cancer (AJCC) staging system.

The study was reviewed and approved by the local institution review board at King Hussain Cancer Center KHCC. 


\section{Molecular Testing For Somatic Genetic Changes}

All the retrieved Hematoxylin and Eosin (H\&E) stained sections for the cohort cases were reviewed separately by two experienced histopathologists in endocrine pathology. The pathology diagnoses were reviewed and confirmed to be papillary thyroid carcinoma.

The most appropriate slide for BRAF molecular testing was determined based on the percentage of primary thyroid tumor and lymph node metastasis if present. Ten percent was deemed as minimal accepted tumor percentage on the selected slides. Five sections of approximately 5 to 10 micrometer thickness were sectioned from the formalin fixed paraffin embedded (FFPE) tumor tissue corresponding to the selected slides. Sectioned tissue was collected in Eppendorf tubes with the appropriate labelling. The deoxyribonucleic acid (DNA) was extracted and purified using the QIAamp(r) DNA Mini Kit (Qiagen). Samples were assessed for DNA concentration and purity using the NanoDrop(r) ND-1000 spectrophotometer. BRAF mutation testing was performed using therascreen(r) BRAF RGQ PCR Kit on the QIAGEN Rotor-Gene Q MDx instrument, that is designed to detect five somatic mutations in the BRAF gene including: V600E, V600E complex (V600EC), V600D, V600K, and V600R.

\section{Statistical analysis}

Patients characteristics, clinical, pathological findings, and clinical outcomes were collected in a retrospective manner. Data was analysed using the software package SPSS 24 (Chicago, Illinois, USA). Results were expressed as medians and interquartile ranges (IQR) or mean and standard deviation (SD). Comparison between the two groups was performed using the $\chi 2$ test for categorical variables and the Ttest for continuous variables. Survival functions were compared using the non-parametric Kaplan-Meier estimator. Clinical and pathological predictors of overall and disease-free survival were analyzed using univariate and multivariate Cox proportional-hazards models. Significance was defined as $\mathrm{P}$ value less than 0.05 . Statistically significant factors on univariate analysis were included in the multivariate model.

\section{Results}

\section{Patient's characteristics}

A hundred and twenty-eight patients were included with a mean age of thirty-eight years $( \pm 13.8)$ at the time of diagnosis. Forty-one (32\%) patients were men and eighty-seven (68\%) were women. Patients were followed for a median of fifty-month post-surgical resection.

The mean size of the primary tumour was $2.6 \mathrm{~cm}( \pm 2.2)$. Eighty-six percent of the patients were staged as stage I PTC. Of the 128 patients with conventional PTC, BRAF V600E mutation was found in $91(71 \%)$ patients. Table 1 lists the characteristics of the 128 patients with conventional PTC included in the study. 
Table 1

Clinicopathological characteristics

\begin{tabular}{|c|c|c|}
\hline & Variables & $\begin{array}{l}\text { Total } \\
\mathrm{N}=128(\%)\end{array}$ \\
\hline \multirow[t]{2}{*}{ BRAF gene mutation } & Positive & $91(71.1)$ \\
\hline & Negative & $37(28.9)$ \\
\hline \multirow[t]{2}{*}{ Age } & $<55$ years & $113(88.3)$ \\
\hline & $\geq 55$ years & $15(11.7)$ \\
\hline \multirow[t]{2}{*}{ Gender } & Male & $41(32)$ \\
\hline & Female & $87(68)$ \\
\hline \multirow[t]{2}{*}{ Extra-thyroidal extension } & True & $32(25)$ \\
\hline & False & $96(75)$ \\
\hline Family history & Positive & $9(7)$ \\
\hline Lymph node & Positive & $68(53)$ \\
\hline Multi-Nodular goiter & Concomitant & $12(9.4)$ \\
\hline Hashimoto Thyroiditis & Concomitant & $23(18)$ \\
\hline \multirow[t]{4}{*}{ Pathology stage } & I & $110(85.9)$ \\
\hline & II & $12(9.4)$ \\
\hline & III & $1(0.8)$ \\
\hline & IV & $5(3.9)$ \\
\hline \multirow{2}{*}{$\begin{array}{l}\text { Extent of surgery } \\
\text { (Total Thyroidectomy) }\end{array}$} & Without Neck Dissection & $50(39.1)$ \\
\hline & With neck dissection & $77(60.2)$ \\
\hline \multirow[t]{4}{*}{ Subtype of papillary thyroid cancer } & Insular & $1(0.8)$ \\
\hline & Follicular & $4(3.1)$ \\
\hline & Capsular & $11(8.6)$ \\
\hline & Classic & $112(87.5)$ \\
\hline \multirow[t]{2}{*}{ Tumor size $(\mathrm{cm})$} & Mean (SD) & $2.62(2.17)$ \\
\hline & Median (Range) & $2(0-16)$ \\
\hline \multirow[t]{2}{*}{ Bilateral } & True & $26(20.3)$ \\
\hline & False & $102(79.7)$ \\
\hline
\end{tabular}




\begin{tabular}{|lll|}
\hline & Variables & Total \\
& & $\mathbf{N}=\mathbf{1 2 8}(\%)$ \\
\hline Multifocal & True & $54(42.2)$ \\
& False & $74(57.8)$ \\
\hline
\end{tabular}

\section{Association Of Braf V600e With Clinicopathological Features In Ptcs}

The various clinicopathological characteristics were compared between patients with PTC harboring BRAF V600E mutation and those without (Table 2). The age \& sex were not significantly different between the two groups (with or without BRAF V600E mutation). Patients with BRAF V600E mutation were similar to BRAF V600E-negative patients with regards to lymph node metastasis $(57.1 \%$ vs. $43.2 \%, P=0.36)$, extra-thyroidal extension $(34.1 \%$ vs. $35 \%, P=0.90)$, positive family history $(8.8 \%$ versus $2.7 \%$ respectively, $\mathrm{P}=0.22)$, multifocality ( $44 \%$ vs $37.8 \%, \mathrm{P} 0.52)$, and the extent of neck dissection. The BRAF negative tumors were significantly larger than the BRAF positive $(3.47 \mathrm{~cm}$ versus $2.31 \mathrm{~cm}$ respectively, $P=0.009)$. 
Table 2

Patients characteristics based on BRAF status

\begin{tabular}{|c|c|c|c|c|c|}
\hline \multicolumn{2}{|l|}{ Variable vs BRAF Status } & \multirow{2}{*}{$\begin{array}{l}\text { Total } \\
\mathrm{N}(\%) \\
128(100)\end{array}$} & \multirow{2}{*}{$\begin{array}{l}\text { Positive } \\
\text { N (\%) } \\
91(71.1)\end{array}$} & \multirow{2}{*}{$\begin{array}{l}\text { Negative } \\
\mathrm{N}(\%) \\
37(28.9)\end{array}$} & \multirow{2}{*}{$\begin{array}{l}P \\
\text { value }\end{array}$} \\
\hline & & & & & \\
\hline \multirow[t]{2}{*}{ Gender } & Male & $41(32)$ & $28(30.8)$ & $13(35.1)$ & \multirow[t]{2}{*}{0.63} \\
\hline & Female & $87(68)$ & $63(69.2)$ & $24(64.9)$ & \\
\hline \multicolumn{2}{|l|}{ Positive family history } & $9(7)$ & $8(8.8)$ & $1(2.7)$ & 0.22 \\
\hline Age & Mean (SD) & $\begin{array}{l}37.85 \\
(13.75)\end{array}$ & $\begin{array}{l}38.54 \\
(13.58)\end{array}$ & $\begin{array}{l}36.16 \\
(14.22)\end{array}$ & 0.37 \\
\hline \multirow[t]{2}{*}{ Primary tumor size $(\mathrm{cm})$} & Mean (SD) & 2.62 & 2.31 & 3.47 & \multirow[t]{2}{*}{0.00} \\
\hline & & $(2.17)$ & $(1.67)$ & $(3.04)$ & \\
\hline \multirow[t]{2}{*}{ Lymph node } & Positive & $68(53)$ & $52(57.1)$ & $16(43.2)$ & \multirow[t]{2}{*}{0.36} \\
\hline & Negative & $57(44.5)$ & $37(40.7)$ & $2(5.4)$ & \\
\hline \multicolumn{2}{|l|}{ Extra-Thyroidal extension } & $44(34.4)$ & $31(34.1)$ & $13(35)$ & 0.90 \\
\hline \multirow[t]{2}{*}{ Total thyroidectomy } & $\begin{array}{l}\text { Without neck } \\
\text { dissection }\end{array}$ & $50(39.1)$ & $35(38.5)$ & $15(40.5)$ & \multirow[t]{2}{*}{0.27} \\
\hline & $\begin{array}{l}\text { With neck } \\
\text { dissection }\end{array}$ & $77(60.2)$ & $56(51.5)$ & $21(56.8)$ & \\
\hline \multicolumn{2}{|l|}{ Concomitant Hashimoto } & $23(18)$ & $13(14.3)$ & $10(27)$ & 0.08 \\
\hline \multicolumn{2}{|l|}{ Hyperthyroidism } & $11(8.6)$ & $7(7.7)$ & $4(10.8)$ & 0.56 \\
\hline \multicolumn{2}{|l|}{ Multifocality } & $54(42.2)$ & $40(44)$ & $14(37.8)$ & 0.52 \\
\hline \multirow{4}{*}{$\begin{array}{l}\text { Subtype of papillary thyroid } \\
\text { cancer }\end{array}$} & Insular & $1(0.8)$ & $0(0.0)$ & $1(2.7)$ & \multirow[t]{4}{*}{0.276} \\
\hline & Follicular & $4(3.1)$ & $2(2.2)$ & $2(5.4)$ & \\
\hline & Capsular & $11(8.6)$ & $7(7.7)$ & $4(10.8)$ & \\
\hline & Classic & $112(87.5)$ & $82(90.1)$ & $30(81.1)$ & \\
\hline \multicolumn{2}{|l|}{ Multicentricity } & $26(20.3)$ & 19 (20.9) & 7 (18.9) & 0.80 \\
\hline
\end{tabular}

With a median follow-up of fifty months, the two groups showed similar 5-year Disease-free survival (DFS) $(P=0.37)$ (Fig. 1) and Overall survival $(P=0.94)$ (Fig. 2). 
To assess the effect of several risk factors on survival time in patients with PTC, the disease-free and overall survival analysis was extended using univariate and multivariate Cox regression model. The BRAF status, gender, family history, concomitant multinodular goiter, Hashimoto Thyroiditis, multifocality, multicentricity, and thyroglobulin level post-operatively, and extent of neck dissection were entered into the model. Female gender was the only factor significantly associated with improved disease-free survival on univariate (Hazard Ratio: $0.637, \mathrm{P}=0.05$ ). None was associated with improved survival on multivariate analysis. (Table 3 ).

\section{Table 3: Factors associated with Disease-Free survival}

\begin{tabular}{|c|c|c|c|c|c|c|c|c|}
\hline \multirow[t]{3}{*}{ Factor } & \multicolumn{8}{|c|}{ Univariate Analysis } \\
\hline & \multirow{2}{*}{$\begin{array}{l}\text { Hazard } \\
\text { Ratio }\end{array}$} & \multicolumn{2}{|l|}{$95 \% \mathrm{Cl}$} & \multirow{2}{*}{$\begin{array}{l}\text { P- } \\
\text { Value }\end{array}$} & \multirow{2}{*}{$\begin{array}{l}\text { Hazard } \\
\text { Ratio }\end{array}$} & \multicolumn{2}{|l|}{$95 \% \mathrm{Cl}$} & \multirow{2}{*}{$\begin{array}{l}\mathrm{P} \text { - } \\
\text { Value }\end{array}$} \\
\hline & & Lower & Upper & & & Lower & Upper & \\
\hline BRAF status & 0.731 & 0.471 & 1.134 & 0.162 & & & & \\
\hline Gender - Female & 0.637 & 0.404 & 1.004 & 0.052 & 0.687 & 0.435 & 1.087 & 0.109 \\
\hline $\begin{array}{l}\text { Family history - } \\
\text { Negative }\end{array}$ & 0.767 & 0.383 & 1.535 & 0.454 & & & & \\
\hline Age & 1.124 & 0.679 & 1.861 & 0.650 & & & & \\
\hline $\begin{array}{l}\text { Extra-Thyroidal } \\
\text { extension - Negative }\end{array}$ & 0.893 & 0.582 & 1.370 & 0.604 & & & & \\
\hline $\begin{array}{l}\text { Extent of Neck } \\
\text { Dissection }\end{array}$ & 1.975 & 1.262 & 3.090 & 0.003 & 1.910 & 1.216 & 3.000 & 0.005 \\
\hline $\begin{array}{l}\text { Concomitant } \\
\text { multinodular goiter }\end{array}$ & 1.833 & 0.945 & 3.553 & 0.073 & & & & \\
\hline $\begin{array}{l}\text { Concomitant } \\
\text { Hashimoto }\end{array}$ & 0.842 & 0.513 & 1.380 & 0.495 & & & & \\
\hline Multifocality & 0.814 & 0.543 & 1.221 & 0.320 & & & & \\
\hline Multicentricity & 0.741 & 0.447 & 1.229 & 0.246 & & & & \\
\hline $\begin{array}{l}\text { Thyroglobulin Level } \\
\text { (Post-Op) }\end{array}$ & 1.001 & 0.999 & 1.004 & 0.303 & & & & \\
\hline
\end{tabular}

As for the overall survival (Table 4); Patients diagnosed below the age of 50 were significantly associated with improved overall survival on univariate (Hazard ratio $0.031, P=0.001$ ) and multivariate analysis (Hazard ratio 0.037, P = 0.003). 
Table 4: Factors associated with overall survival

\begin{tabular}{|c|c|c|c|c|c|c|c|c|}
\hline \multirow[t]{3}{*}{ Factor } & \multicolumn{4}{|c|}{ Univariate analysis } & \multicolumn{4}{|c|}{ Multivariate analysis } \\
\hline & \multirow{2}{*}{$\begin{array}{l}\text { Hazard } \\
\text { ratio }\end{array}$} & \multicolumn{2}{|l|}{$95 \% \mathrm{Cl}$} & \multirow{2}{*}{$\begin{array}{l}\text { P- } \\
\text { value }\end{array}$} & \multirow{2}{*}{$\begin{array}{l}\text { Hazard } \\
\text { ratio }\end{array}$} & \multicolumn{2}{|l|}{$95 \% \mathrm{Cl}$} & \multirow{2}{*}{$\begin{array}{l}\mathrm{P} \text { - } \\
\text { value }\end{array}$} \\
\hline & & Lower & Upper & & & Lower & Upper & \\
\hline BRAF status & 0.940 & 0.182 & 4.866 & 0.941 & & & & \\
\hline Gender-Female & 6.441 & 1.240 & 33.449 & 0.027 & 7.841 & 1.195 & 51.466 & .032 \\
\hline $\begin{array}{l}\text { Family history - } \\
\text { Negative }\end{array}$ & 5.660 & 1.036 & 30.934 & 0.045 & 2.367 & .409 & 13.705 & 0.336 \\
\hline Age $<50$ years & 0.031 & 0.004 & 0.261 & 0.001 & 0.037 & 0.004 & 0.330 & 0.003 \\
\hline $\begin{array}{l}\text { Extra-Thyroidal } \\
\text { extension }\end{array}$ & 0.211 & 0.041 & 1.089 & 0.063 & & & & \\
\hline $\begin{array}{l}\text { Extent of Neck } \\
\text { Dissection }\end{array}$ & 1.100 & 0.230 & 5.268 & 0.905 & & & & \\
\hline $\begin{array}{l}\text { Concomitant } \\
\text { multinodular goiter }\end{array}$ & 0.617 & 0.072 & 5.286 & 0.659 & & & & \\
\hline $\begin{array}{l}\text { Concomitant } \\
\text { Hashimoto }\end{array}$ & 0.990 & 0.116 & 8.481 & 0.993 & & & & \\
\hline Multifocality & 0.736 & 0.149 & 3.649 & 0.708 & & & & \\
\hline Multicentricity & 0.474 & 0.087 & 2.591 & 0.389 & & & & \\
\hline $\begin{array}{l}\text { Thyroglobulin Level } \\
\text { (Post-Op) }\end{array}$ & 1.002 & 0.996 & 1.007 & 0.556 & & & & \\
\hline
\end{tabular}

\section{Discussion}

In this study, we examined the clinicopathological factors associated with BRAF V600E mutation. We also explored the relationship between BRAF V600E and the oncological outcomes in PTC. The BRAF V600E mutation is considered a specific diagnostic and prognostic marker in PTC. V600E is a point mutation at codon 600 of BRAF gene. This causes a constitutive activation of the BRAF kinase and an uncontrolled activation of the MAP Kinase signalling pathway.

Previous publications have linked BRAF mutation with worse prognostic features. This includes age at diagnosis, male sex, multifocal tumor, and advanced TNM stage ${ }^{10,11,14-18}$. Xing et al reported a significant association between BRAF mutation, adjacent structures invasion, and lymph node metastasis 10. Other reports found BRAF mutation to independently predict Central lymph nodes metastasis ${ }^{18}$. At multivariate analysis of BRAF V600E mutation showed an independent correlation with worst outcome. 
Moreover, the survival curves of PTC patients showed a worse survivor in the BRAF V600E-mutated group 19

These reported outcomes are in contradiction with the result of our current study. Other large retrospective studies were consistent with our findings and failed to corroborate the above reported associations $12,13,20-22$

Ito et al investigated BRAF V600E mutation in 631 patients with papillary carcinoma with a median follow-up of 83 months. The prevalence of BRAF V600E mutation was $38.4 \%$. BRAF V600E prevalence was not significantly associated with cases demonstrating high-risk biological features such as clinically apparent lymph node metastasis, massive extrathyroid extension, advanced age, distant metastasis at surgery, and advanced stage. The disease-free survival of patients with BRAF V600E mutation did not differ from those without mutation ${ }^{22}$. These findings along with our results indicate that, although BRAF V600E mutation may play some roles in local carcinoma development, there is no significant evidence associating it with aggressive characteristics and poor prognosis.

Studies focusing on Asian populations did not find an association between BRAF V600E mutation and regional lymph node metastasis. An example of such study by Junliang et al reported the outcome of 150 PTC cases. Eighty percent of the primary tumors contained a BRAF V600E mutation. Lymph node metastasis was equally distributed in patients with or without BRAF V600E mutation ${ }^{23}$. This may suggest a difference in the mutation's behaviour based on the racial background.

The overall significance of BRAF mutation in PTC is open to debate. In addition, the incidence and clinical impact of BRAF V600E mutation among PTC patients from Middle Eastern races remain unknown. To our knowledge; this is the first cohort investigating the relation between BRAF mutation \& papillary thyroid cancer in the Middle Eastern population. The limitation of our study is its retrospective nature, single institution \& small sample size.

\section{Conclusions}

Despite the high percentage of PTCs harboring BRAF V600E; mutation positivity did not affect lymph node involvement, loco-reginal recurrence, distant metastasis, overall and disease-free survival. These results support the diversity of BRAF V600E significance among various ethnicities.

\section{Declarations}

\section{Acknowledgements: NA}

\section{Authors' contributions:}

All authors contributed to the study conception and design. Material preparation, data collection and analysis were performed by MM, HKN, TS, MM and RI. The first draft of the manuscript was written by TS, 
EY, AT, HH, AJ. All authors commented on previous versions of the manuscript. All authors read and approved the final manuscript.

Ethics approval and consent to participate: This study was approved by the Institutional Review Board (IRB) at the King Hussein Cancer Center (Approval \#: 15KHCC101).

Consent for publication: Not Applicable, This is a retrospective Study.

Data availability: The datasets used and/or analysed during the current study are available from the corresponding author on reasonable request.

Competing interests: The authors declare that they have no conflicts of interest.

Funding information: This study was funded by King Hussein Cancer Center (Grant Number: 15KHCC101).

\section{Ethics declarations:}

This is a retrospective chart review study approved by the Institutional Review Board (IRB) at King Hussein Cancer Center (KHCC). IRB (Ref: 15KHCC101). The KHCC IRB is guided by the principles described in the World Medical Association's Declaration of Helsinki (1964) and its amendments.

Because of the retrospective nature of the study and the lack of personal or clinical details of participants that compromise anonymity, consent was waived and the study was approved by King Hussein Cancer Center Institutional Review Board (IRB). The datasets used and/or analysed during the current study are available from the corresponding author on reasonable request.

\section{References}

1. Pacini, F. \& Castagna, M. G. Approach to and Treatment of Differentiated Thyroid Carcinoma. Medical Clinics of North America 96, 369-383 (2012).

2. Nimri, A. A., K; Assad M. Jordan Cancer Registery Cancer Incidence in Jordan - 2015, https://moh.gov.jo/Echobusv3.0/SystemAssets/fbd82c46-6851-40d5-ae9f-651dfc9515ec.pdf (2015).

3. Chen, A. Y., Jemal, A. \& Ward, E. M. Increasing incidence of differentiated thyroid cancer in the United States, 1988-2005. Cancer 115, 3801-3807 (2009).

4. Davies, L. \& Welch, H. G. Increasing Incidence of Thyroid Cancer in the United States, 1973-2002. JAMA 295, 2164 (2006).

5. Grodski, S. et al. Increasing incidence of thyroid cancer is due to increased pathologic detection. Surgery 144, 1038-1043 (2008).

6. Yeung, M. J. \& Pasieka, J. L. Well-differentiated thyroid carcinomas: management of the central lymph node compartment and emerging biochemical markers. Journal of oncology 2011, 705305- 
705305 (2011).

7. Kim, T. H. et al. The association of the BRAFV600E mutation with prognostic factors and poor clinical outcome in papillary thyroid cancer. Cancer 118, 1764-1773 (2011).

8. Hundahl, S. A., Fleming, I. D., Fremgen, A. M. \& Menck, H. R. A National Cancer Data Base report on 53,856 cases of thyroid carcinoma treated in the U.S., 1985-1995. Cancer 83, 2638-2648 (1998).

9. Shi, C. L., Sun, Y., Ding, C., Lv, Y. C. \& Qin, H. D. Correlation between the BRAF V600E mutation status and the clinicopathologic features of papillary thyroid carcinoma. Genetics and Molecular Research 14, 7377-7385 (2015).

10. Xing, M. et al. BRAF Mutation Predicts a Poorer Clinical Prognosis for Papillary Thyroid Cancer. The Journal of Clinical Endocrinology \& Metabolism 90, 6373-6379 (2005).

11. Yip, L. et al. Optimizing surgical treatment of papillary thyroid carcinoma associated with BRAF mutation. Surgery 146, 1215-1223 (2009).

12. Kim, T. Y. et al. The BRAFV600E mutation is not associated with poor prognostic factors in Korean patients with conventional papillary thyroid microcarcinoma. Clinical Endocrinology 63, 588-593 (2005).

13. Brzezianska, E. et al. Investigation of V600E BRAF mutation in papillary thyroid carcinoma in the Polish population. Neuro Endocrinol Lett 28, 351-359 (2007).

14. Xing, M. BRAF mutation in thyroid cancer. Endocrine Related Cancer 12, 245-262 (2005).

15. Lin, K.-L. et al. The BRAF Mutation Is Predictive of Aggressive Clinicopathological Characteristics in Papillary Thyroid Microcarcinoma. Annals of Surgical Oncology 17, 3294-3300 (2010).

16. Chakraborty, A. et al. BRAF V600E Mutation in Papillary Thyroid Carcinoma: Significant Association with Node Metastases and Extra Thyroidal Invasion. Endocrine Pathology 23, 83-93 (2011).

17. Kim, S.j. et al. BRAFV600E Mutation is Associated with Tumor Aggressiveness in Papillary Thyroid Cancer. World Journal of Surgery 36, 310-317 (2011).

18. Howell, G. M. et al. BRAF V600E Mutation Independently Predicts Central Compartment Lymph Node Metastasis in Patients with Papillary Thyroid Cancer. Annals of Surgical Oncology 20, 47- 52 (2012).

19. Elisei, R. et al. BRAFV600E Mutation and Outcome of Patients with Papillary Thyroid Carcinoma: A 15-Year Median Follow-Up Study. The Journal of Clinical Endocrinology \& Metabolism 93, 39433949 (2008).

20. Fugazzola, L. et al. Correlation between B-RAFV600E mutation and clinico-pathologic parameters in papillary thyroid carcinoma: data from a multicentric Italian study and review of the literature. Endocrine-Related Cancer, 455-464 (2006).

21. Fugazzola, L. et al. BRAF mutations in an Italian cohort of thyroid cancers. Clinical Endocrinology 61, 239-243 (2004).

22. Ito, Y. et al. BRAF Mutation in Papillary Thyroid Carcinoma in a Japanese Population: Its Lack of Correlation with High-Risk Clinicopathological Features and Disease-Free Survival of Patients. Endocrine Journal 56, 89-97 (2009). 
23. Lu, J. et al. Association between BRAF V600E mutation and regional lymph node metastasis in papillary thyroid carcinoma. Int J Clin Exp Pathol 8, 793-799 (2015).

\section{Figures}

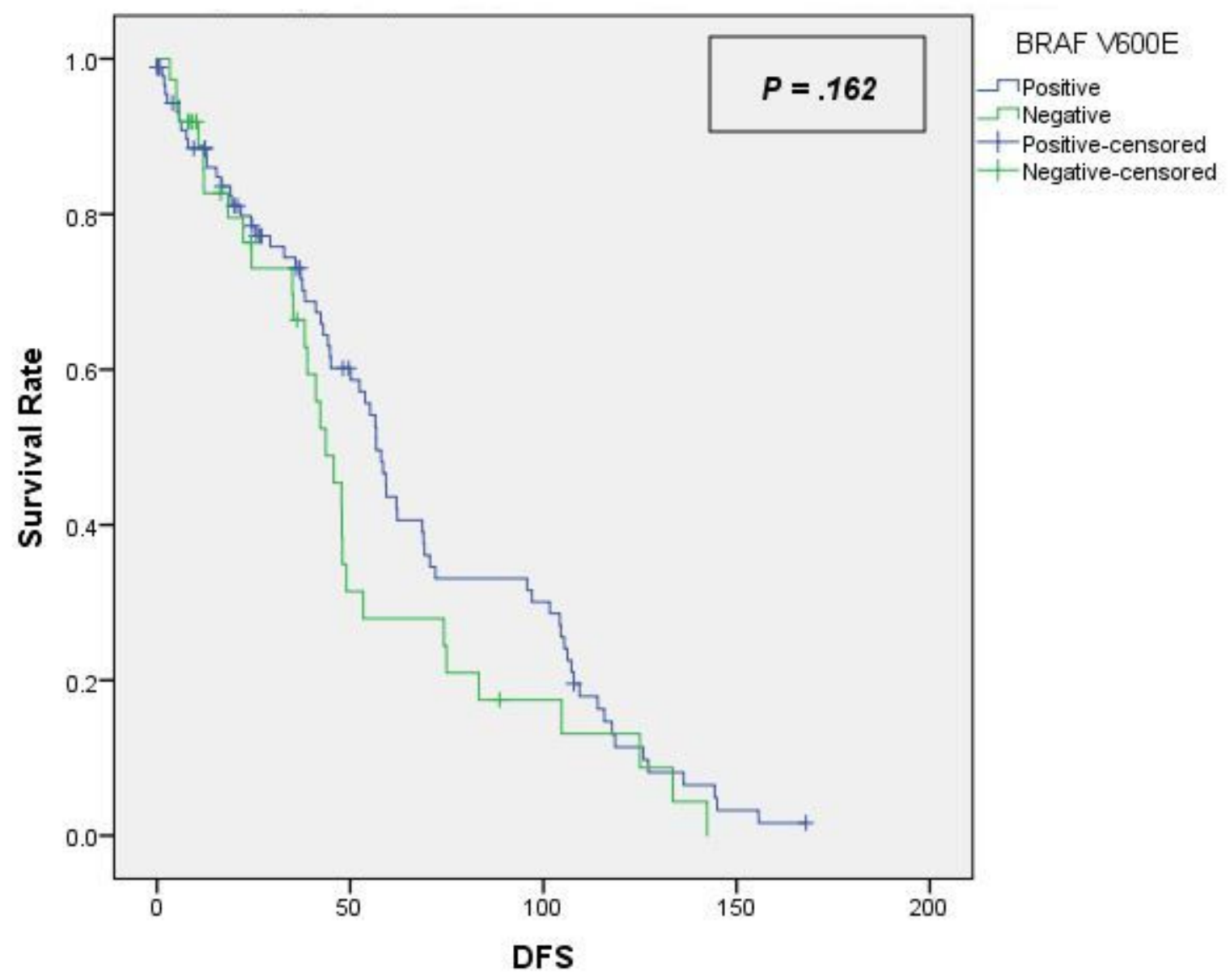

Figure 1

Kaplan-Meier curve for the Disease-free survival 


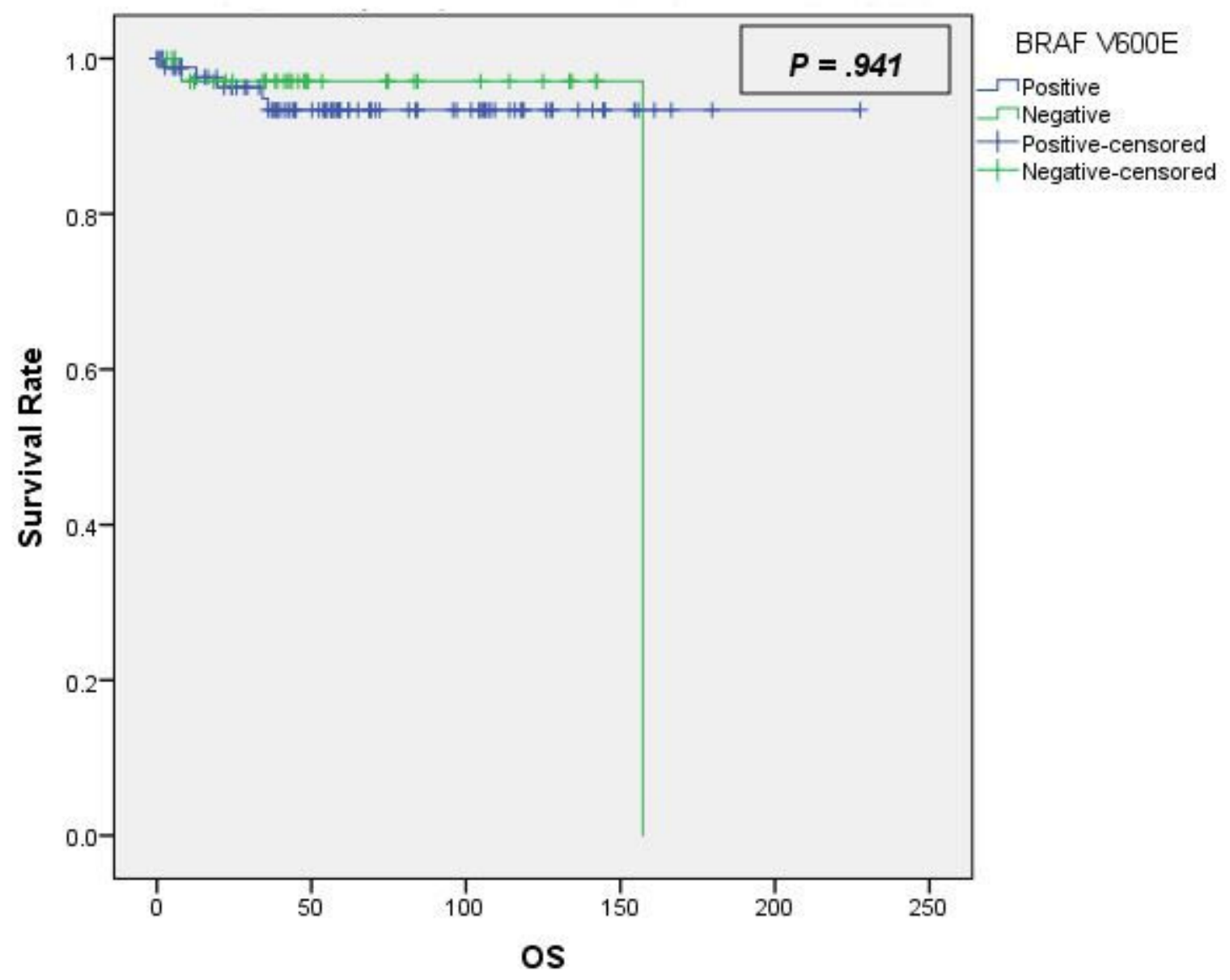

Figure 2

Kaplan-Meier curve for the overall survival 